\title{
A fungal scent from the cheese
}

\section{Kovács, Ákos T.}

\section{Published in:}

Environmental Microbiology

Link to article, DOI:

10.1111/1462-2920.15267

Publication date:

2020

\section{Document Version}

Peer reviewed version

Link back to DTU Orbit

Citation (APA):

Kovács, Á. T. (2020). A fungal scent from the cheese. Environmental Microbiology, 22(11), 4524-4526. https://doi.org/10.1111/1462-2920.15267

\section{General rights}

Copyright and moral rights for the publications made accessible in the public portal are retained by the authors and/or other copyright owners and it is a condition of accessing publications that users recognise and abide by the legal requirements associated with these rights.

- Users may download and print one copy of any publication from the public portal for the purpose of private study or research.

- You may not further distribute the material or use it for any profit-making activity or commercial gain

- You may freely distribute the URL identifying the publication in the public portal

If you believe that this document breaches copyright please contact us providing details, and we will remove access to the work immediately and investigate your claim. 
$1 \quad$ Highlight on Cosetta et al doi: 10.1111/1462-2920.15223

2

3 A fungal scent from the cheese

4

5 Ákos T. Kovács*

6

7 Bacterial Interactions and Evolution Group, DTU Bioengineering, Technical University of Denmark, $8 \quad 2800$ Kongens Lyngby, Denmark

9

10 * For correspondence. E-mail atkovacs@dtu.dk; Tel. (+45) 45252727

11

12 Running title: Fungal volatile affected bacterial growth

13 Keywords: bacteria-fungi interaction; cheese rind; microbiome; community assembly; volatiles 14 
17 Assembly of microbial communities is shaped by various physical and chemical factors deriving

18 from their environment, including other microbes inhabiting the certain niche. In addition to direct

19 cell-cell contacts, primary and secondary metabolites impact the growth of microbial community

20 members. Metabolites might act as growth-promoting (e.g. cross-feeding), growth-inhibiting (e.g.

21 antimicrobials), or signaling molecules. In multi-species microbial assemblies, secreted metabolites

22 might influence specific members of the community, altering species abundances and therefore

23 the functioning of these microcosms. In the current issue, Cosetta and colleagues describe a

24 unique volatile metabolite-mediated cross-kingdom interaction that shapes the cheese rind

25 community assembly. The study paves the way of our understanding how fungus-produced

26 volatile compounds promote the growth of a certain bacterial genus, a principal connection

27 between community members of the cheese rind.

28 
Main text

Since the first formulation of the microbiological tenet 'Everything is everywhere, but, the environment selects' by Baas Becking motivated by Martinus Beijerinck's work (Beijerinck, 1913; Baas-Becking, 1934; De Wit and Bouvier, 2006), microbial ecologists have been researching the factors determining microbial community assemblies. Complex association of diverse microbes in a certain niche is driven by numerous influences from the environment, physical, chemical and biological factors including temperature, humidity, nutrient availability, and various metabolites from other organisms. Microbes can inhibit the growth of each other by producing specific or general antimicrobial compounds, they can gain by acquiring beneficial metabolites secreted by surrounding companions, in specific cases resulting in complex cross-feeding networks (D'Souza et al., 2018). In addition, the secreted primary- and secondary-metabolites could convey signaling function that affect development of other microbes (Pishchany and Kolter, 2020). To gain deeper understanding how the 'environment selects', simplified microbial systems are inspected ranging from two or very few members to complex communities.

Cheese rind provides a relatively simple, tractable system that repetitively assembles into defined composition of communities dominated by key genera, therefore allows examining microbial succession (Wolfe et al., 2014). The cheese diversity, including smell and taste, around the world is in principle defined by the microorganisms accompanying the fermentation process that that is thought to be invested and used since for 10.000 years. Originating from both natural 'contaminating' and inoculated microorganisms, the cheese rind community is dominated by few prokaryotic phyla (Firmicutes, Actinobacteria, Proteobacteria and Bacteriodes) and eukaryotes (yeast and molds) that forms a dense, biofilm-like layer around the cheese. The composition of such 
rind cheese community is dynamic during the fermentation process and defined by abiotic and biotic factors. This exceptional experimental system offers a platform to study interaction among fungi and bacteria. The intricate interplay between these two kingdoms of life has been recently exploited to understand the influence of diverse metabolites in microbial community dynamics. What determines the abundances of microbial genera during cheese rind maturation? How do specific metabolites impact the growth of microbes during the cheese ripening?

Cosetta and colleagues (2020) answer these questions and reveal how volatile organic compounds (VOCs) produced by widespread cheese rind fungi specifically stimulate the growth of specific cheese rind bacteria (Fig. 1). Exploiting a novel 'microtiter-plate sandwich' system, in which volatile producers and responders are physically separated in the wells of the bottom and top plates, respectively, but having common airspace, the influence of VOCs produced by five different cheese rind derived fungi was inspected on the growth of bacterial isolates inoculated on cheese curd agar. Intriguingly, the growth of various Vibrio species was generally promoted by the VOCs produced by cheese rind fungi, including Debaryomyces, Penicillium, and Galactomyces isolates, but not when bacteria and fungi were co-cultured. The promotion of Vibrio growth was also observed when a synthetic bacterial community, representing a typical rind bacteria composition, was exposed to the VOCs of the fungi. Characterization of the transcriptional profile of Vibrio population revealed that VOCs promote the expression of genes involved in glyoxylate shunt, which allows bacteria to utilize acetate and other fatty acids as carbon source. Indeed, esters and fatty acids, like acetic acid, are widely detected in ripening cheeses, contributing to the sweet, fruity perception of surface-ripened cheeses (Urbach, 1997). In line with this general observation, acetate-containing fatty acids could be detected using gas chromatography/mass spectrometry in the headspace of cheese rind fungi (Cosetta et al., 2020). Finally, acetic acid, as well as heptyl acetate and methyl isobutyrate 
specifically increased Vibrio growth and shifted the abundance of Vibrio within the synthetic microbial community.

The work of Cosetta and colleagues provides a valuable insight on VOC-mediated microbial interaction. Moreover, it reveals how growth promotion of specific genus shifts the composition of a synthetic microbial consortium and pinpoints the direct stimulation of growth by acetatecontaining VOCs though metabolism in the glyoxylate shunt. VOCs have diverse impact on microbial growth and development, acting as nutrients, environmental modulators or signal molecules (Tyc et al., 2017). Acetate-containing VOCs has been detected in numerous microbial systems (Ryu et al., 2020), and while acetate acts a metabolic signal inside bacterial cells (Wolfe, 2005), among microbial cells, it can also act as signaling compound, altering development and differentiation, for example stimulating biofilm formation (Chen et al., 2015). While the broad impact of this small volatile molecule has been previously suggested, Cosetta and colleagues have uniquely demonstrated the impact of microbial community composition.

The creation of synthetic microbial communities provides a tractable system to dissect the influence of various VOCs or generally of secondary metabolites to reveal the true nature of these compounds in nature. The activity of secondary metabolites has been traditionally explored in pairwise interactions and only recently, the influence of these specialized metabolites examined on microbial communities (Kiesewalter et al., 2020). Once thought to act as fierce antimicrobial compounds, the real ecological impact of secondary metabolites within complex microbial communities still to be explored. The scent of the cheese is not only appreciated by its consumers, but also by the microbial community during the anciently acquired food fermentation process. 


\section{Acknowledgements}

98 ÁTK was supported by the Danish National Research Foundation (DNRF137) for the Center for

99 Microbial Secondary Metabolites (CeMiSt).

100

101 Competing Interests

102 The author has no competing interests to declare.

103 


\section{References}

Baas-Becking, L.G.M. (1934) Geobiologie of inleiding tot de milieukunde. The Hague, the Netherlands: W.P. Van Stockum \& Zoon (in Dutch).

Beijerinck, M.W. (1913) De infusies en de ontdekking der backteriën. Jaarboek van de Koninklijke Akademie van Wetenschappen. Amsterdam, the Netherlands: Müller.

Chen, Y., Gozz, K., Yan, F., and Chai, Y. (2015) Acetic acid acts as a volatile signal to stimulate bacterial biofilm formation. mBio 6: e00392.

Cosetta, C.M., Kfoury, N., Robbat, A., and Wolfe (2020) Fungal volatiles mediate cheese rind microbiome assembly. Environ Microbiol doi: 10.1111/1462-2920.15223.

D’Souza, G., Shitut, S., Preussger, D., Yousif, G., Waschina, S., and Kost, C. (2018) Ecology and evolution of metabolic cross-feeding interactions in bacteria. Nat Prod Rep 35: 455-488.

Kiesewalter, H.T., Lozano-Andrade, C.N., Strube, M.L., and Kovács, Á.T. (2020) Secondary metabolites of Bacillus subtilis impact soil-derived semi-synthetic bacterial community assembly. bioRxiv doi: 10.1101/2020.08.20.259788.

Pishchany, G., and Kolter, R. (2020) On the possible ecological roles of antimicrobials. Mol Microbiol 113: 580-587.

Ryu, C.M., Weisskopf, L., and Piechulla, B. (eds) (2020) Bacterial Volatile Compounds as Mediators of Airborne Interactions. Springer Nature Singapore Pte Ltd.

Tyc, O., Song, C., Dickschat, J.S., Vos, M., and Garbeva, P. (2017) The ecological role of volatile and soluble secondary metabolites produced by soil bacteria. Trends Microbiol 25: 280-292.

Urbach, G. (1997) The flavour of milk and dairy products: II. Cheese: contribution of volatile compounds. Int J Dairy Technol 50: 79-89.

de Wit, R., and Bouvier, T. (2006) "Everything is everywhere, but, the environment selects"; what 
127 did Baas Becking and Beijerinck really say? Environ Microbiol 8: 755-758.

128 Wolfe, A.J. (2005) The acetate Switch. Microbiol Mol Biol Rev 69: 12-50.

129 Wolfe, B.E., Button, J.E., Santarelli, M., and Dutton, R.J. (2014) Cheese rind communities provide 130 tractable systems for in situ and in vitro studies of microbial diversity. Cell 158: 422-433.

131

132 


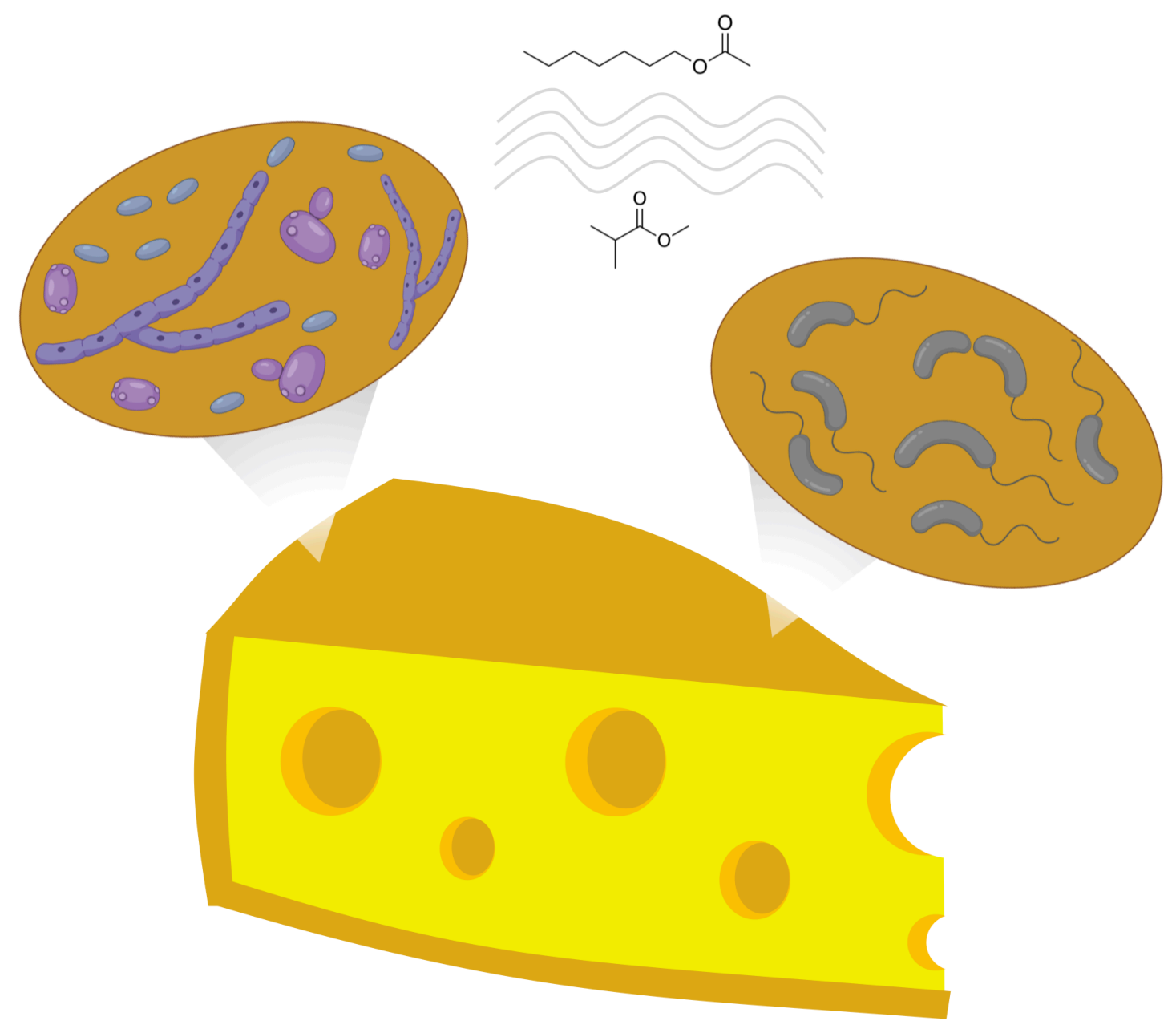

134

135 Fig. 1 VOCs (heptyl acetate and methyl isobutryate) mediated interaction between fungi (left inlet)

136 and bacteria (Vibrio, right inlet). Inlets were prepared on BioRender.com 